\title{
Toxicity of primulic acid 1 against a daphnid species Simocephalus expinosus s.l.
}

Abstract Primulic acid 1 is the main saponin present in Primula elatior. The present study describes the isolation of this amphiphilic compound from primula root. It was performed by ultrasonic maceration, reverse-phase column chromatography and crystallization. Investigations of its physicochemical property are represented by the determination of critical micelle concentration (cmc). The $\mathrm{cmc}$ value of the amphiphile was $9.4 \times 10^{-5} \mathrm{~mol} \cdot \mathrm{dm}^{-3}$. The evaluation of environmental toxicity was performed on a daphnid species Simpocephalus expinosus s.l., which was very sensitive to primulic acids 1. The results from acute immobilisation test show that the tested compound has half maximal effective concentration after 24 hours ( $\left.\mathrm{EC}_{50}-24 \mathrm{~h}\right)$ equal to $6.9 \mathrm{mg} \cdot \cdot^{-1}$. Saponin can be classified as a toxic compound for aquatic organisms.

Keywords Critical micelle concentration-daphnid-ecotoxicology-extraction-primula root

\section{INTRODUCTION}

Primulic acid 1 (primulasaponin 1 or saponin PS4) is the main triterpene saponin from primula roots. This drug is officinal according to the tenth edition of the European Pharmacopoeia (Ph. Eur. 10.0, 2019). The source of the drug is Primula veris or Primula elatior. Both plants are native in Europe and temperate Asia. The main indication for primula root is the treatment of cough. Laboratory studies showed that this drug increased the production of airway secretions, making phlegm less thick and easier to expel. However, no clinical studies were made with the remedy containing primula root only (EMA, 2016).

Chemical structure of primulic acid 1 is depicted in Figure 1. Saponin is composed of two main parts, the hydrophilic and the hydrophobic part. The structure is characteristic for amphiphilic compounds. The lipophilic part consists of a pentacyclic triterpene moiety. The hydrophilic part is represented by saccharides. Galactose, glucose and rhamnose are neutral aldohexoses. However, glucuronic acid is acidic monosaccharide. It can be ionized and transformed from a non-ionic amphiphile to its anionic form. Ionisation of primulic acid 1 improves the solubility of saponin in aqueous media (Böttger et al., 2012).

Increasing use of medicines and nutritional supplements is related to higher environmental risks. Many drugs are produced and used in tonne quantities. They are introduced into the environment and are considered as contaminants of emerging concern. These drugs are responsible for hazards and toxicity towards aquatic and terrestrial living systems (Kar et al., 2020). The influence of pollutants towards environment is evaluated on many bacterial, plant and animal models. One of the aquatic organisms highly recommended for the shortterm toxicity is Daphnia sp. The application of this organism in the tests is regulated by the EC directive No. 1907/2006 of the European parliament and of the council (Regulation (EC) No. 1907/2006).

The aim of the present study is to provide a simple method for the isolation of primulic acid 1 from primula root and the evaluation of its toxicity towards environment. The evaluation

\section{*E-mail:lukac@fpharm.uniba.sk}

2 Open Access. ๑ 2020 European Pharmaceutical Journal, published by Sciendo. (cc)Br-NC-ND This work is licensed under the Creative Commons Attribution-NonCommercialNoDerivatives 3.0 License. 


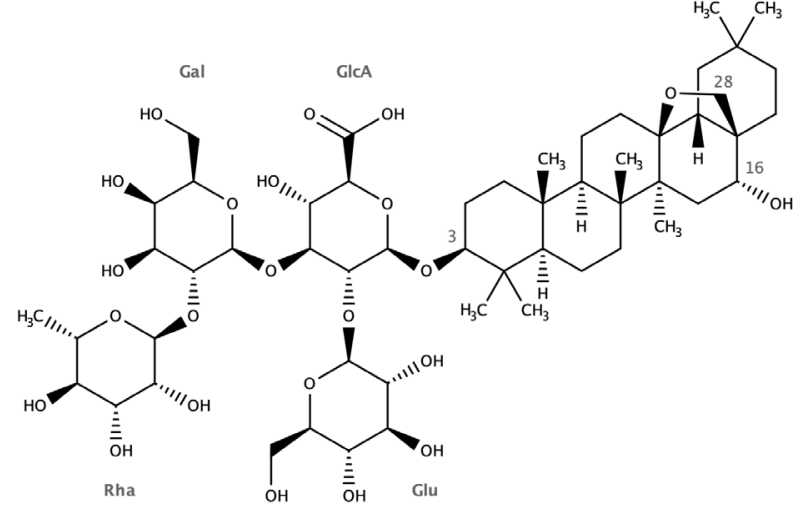

Figure 1. Chemical structure of primulic acid 1.

was performed on an aquatic organism obtained from nature. It is represented by Simocephalus expinosus s.l.

\section{MATERIAL AND METHODS}

\section{Isolation of primulic acid 1}

Primulic acid 1 was isolated from Primula elatior. The plant was collected in Považská Bystrica, Slovakia (WGS84: $\left.49.093457^{\circ} \mathrm{N} ; 18.465616^{\circ} \mathrm{E}\right)$ on March 8, 2018. Powdered root $(20 \mathrm{~g})$ was extracted with methanol $(1 \times 75 \mathrm{ml}, 2 \times 50$ $\mathrm{ml})$. Extraction was performed in ultrasonic bath at r.t. for 10 minutes. Solutions were filtered and $175 \mathrm{ml}$ of $0.5 \%$ solution of formic acid in water was added. The solution was transferred in the column which was filled with $55 \mathrm{~g}$ of $\mathrm{MCl}$ gel CHP20P. The column was eluted gradiently with a solution consisting of $0.5 \%$ formic acid in water and methanol (50:50 $\rightarrow$ 0:100, V/V). Fractions containing primulic acid 1 were collected and evaporated. The dry compound (690 $\mathrm{mg}$ ) was dissolved in methanol $(10 \mathrm{ml})$ and diethyl ether $(100 \mathrm{ml})$ was subsequently added. The precipitate was filtered and dried in vacuum. The amount of isolated primulic acid 1 was $624 \mathrm{mg}$. NMR spectra of the investigated compounds are in accordance with the published data (Siems et al., 1998).

\section{Determination of critical micelle concentration of} primulic acid 1

The equilibrium surface tension measurements were carried out according to the procedure described previously (Lukáč et al., 2020). The Wilhelmy plate technique was used for the determination of the solvent surface tension values. Measurements were performed with a Krüss 100 MK2 tensiometer. The samples were prepared by dissolving primulic acid 1 in ISO water. The stock solutions were prepared in a volumetric flask. The measurements were performed at $25 \pm 0.1^{\circ} \mathrm{C}$. The measurements of equilibrium surface tension were taken repeatedly. The values were recorded every 360 $\mathrm{s}$. The measurement was stopped if the difference between the values of two successive measurements was less than 5 $\times 10^{-5} \mathrm{~N} \cdot \mathrm{m}^{-1}$. The break point of the linear parts of the surface tension vs. log c curve was used for the determination of the critical micelle concentration $(\mathrm{cmc})$.

\section{Acute immobilisation test}

Acute immobilisation test was performed according to the OECD guideline No. 202 (OECD, 2004). Simocephalus expinosus s.l. was used as the investigated organism. Parthenogenetic females were obtained from nature (Lukáč, 2019). Daphnids were determined microscopically (Hudec, 2009). Experiments were performed on juveniles, aged less than 24 hours. ISO water was used as the solvent for cultivation. Potassium dichromate was used as a standard for the determination of viability of daphnids. The dissolved oxygen concentration at the end of the test was determined by the Winkler method. The immobilisation experiments were performed in $30 \mathrm{ml}$ vials. The vials were filled with $10 \mathrm{ml}$ solutions containing 5 juveniles each. The testing was performed in pure ISO solution and at five various concentrations of $\mathrm{K}_{2} \mathrm{Cr}_{2} \mathrm{O}_{7}$ and primulic acid 1 solutions. Each concentration for any compound was tested on 20 juveniles ( $4 \times 5$ juveniles). The temperature during the tests was kept at $21 \pm 1{ }^{\circ} \mathrm{C}$. A 16-hour light and 8-hour dark cycles were applied. The duration of the test was 24 hours. The activity was expressed as the half maximal effective concentration after 24 hours $\left(\mathrm{EC}_{50}-24 \mathrm{~h}\right)$.

\section{RESULTS AND DISCUSSION}

The investigated compound, primulic acid 1, was isolated from the roots of Primula elatior. We applied an improved method of isolation of the saponin. Extraction was performed by methanol. The crude extract was purified using reverse phase $\mathrm{MCl}$ gel CHP20P. Additionally, the saponin was crystalized. The amount of isolated primulic acid 1 was $3.1 \%$. The method applying highly porous styrene-divinylbenzene polymer resin instead of C18-silica (Çalis and Yürüker, 1992; Siems et al. 1998) is sufficient for the purification of primulic acid 1. Structure of primulic acid 1 was confirmed by NMR spectroscopy. Its HSQC spectrum is depicted in Fig. 2. C-H interactions of acetal moieties present in four saccharides are visible in the bottom left corner of Fig. 2 . The signals come from rhamnose $\left(\delta_{\mathrm{H}}=5.28 \mathrm{ppm} ; \delta_{\mathrm{C}}=100.7 \mathrm{ppm}\right)$, galactose $\left(\delta_{\mathrm{H}}\right.$ $\left.=5.16 \mathrm{ppm} ; \delta_{\mathrm{C}}=99.5 \mathrm{ppm}\right)$, glucose $\left(\delta_{\mathrm{H}}=4.85 \mathrm{ppm}\right.$ obscured by solvent; $\left.\delta_{C}=101.2 \mathrm{ppm}\right)$ and glucuronic acids $\left(\delta_{H}=4.50\right.$ ppm; $\left.\delta_{C}=104.4 \mathrm{ppm}\right)$. The presence of glucuronic acid is also confirmed by a characteristic carbon signal of carboxylic group in ${ }^{13} \mathrm{C}$ NMR $\left(\delta_{C}=170.7 \mathrm{ppm}\right)$. The signals depicted in the middle of Fig. 2 mainly arise from $\mathrm{C}-\mathrm{H}$ interactions of sugars. Only four signals represented $\mathrm{C}-\mathrm{H}$ interaction observed in aglycone. They are assigned in Fig. 2 by the number of carbons. On the other side, the signals displayed in the top right corner of Fig. 2 represent mainly $\mathrm{C}-\mathrm{H}$ interactions of aglycone. Only signal with $\delta_{H}=1.27 \mathrm{ppm}$ and $\delta_{C}=16.4 \mathrm{ppm}$ represents atoms of the methyl group of rhamnose. 


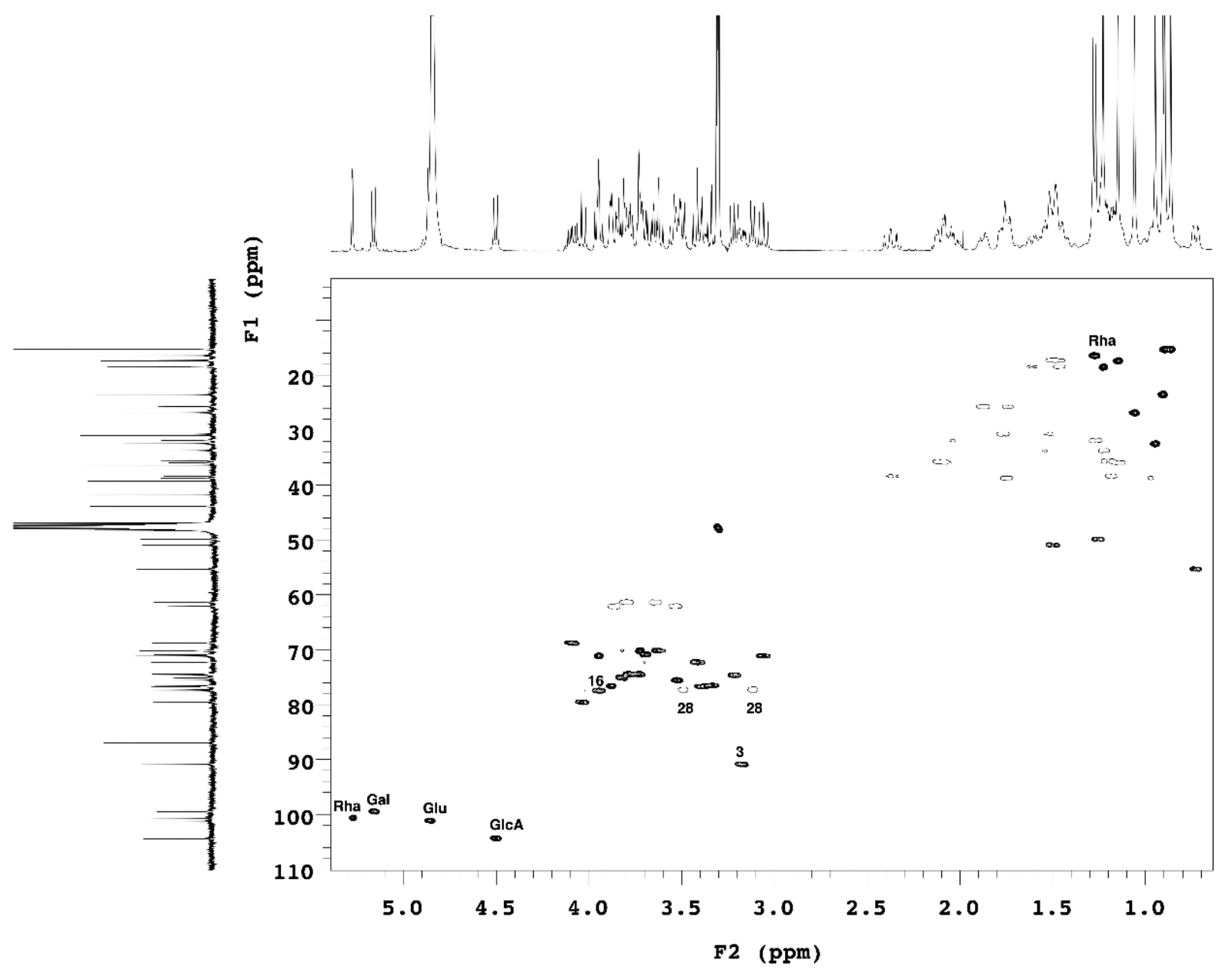

Figure 2. HSQC spectrum of primulic acid 1.

Critical micelle concentration of primulic acid 1 was obtained from surface tension measurements. The measurements were performed in ISO water. The solution contained several salts beside sodium hydrogen carbonate. This salt could react with primulic acid 1 and it caused ionisation of glucuronic acid. This resulted in the formation of anionic amphiphilic compounds - sodium primulate 1 . The $\mathrm{cmc}$ value of the amphiphile was $9.4 \times 10^{-5} \mathrm{~mol} \cdot \mathrm{dm}^{-3}$ (Fig. 3), which is in good agreement with the published data. Böttger et al., (2012) measured cmc of primulic acid in phosphate-buffered saline (PBS) solution. His value of $\mathrm{cmc}$ in PBS was $9.0 \times 10^{-5} \mathrm{~mol} \cdot \mathrm{dm}^{-3}$.

The acute immobilisation test was performed on Simocephalus expinosus s.l. It is a crustacean from family Daphnidae like Daphnia magna, daphnids which is the most commonly used in the ecotoxicological tests. Both daphnids have similar environmental requirements. They can live in small periodic waters and they can be found at a single location (Hudec, 1989). Our results showed that S. expinosus was sensitive to the standard $\mathrm{K}_{2} \mathrm{Cr}_{2} \mathrm{O}_{7}$ in a similar way as D. magna. The $\mathrm{EC}_{50}{ }^{-}$ $24 \mathrm{~h}$ for $\mathrm{S}$. expinosus was $1.77 \mathrm{mg} \cdot \mathrm{I}^{-1}$. It is in the range of 0.6 $-2.1 \mathrm{mg} \cdot \mathrm{l}^{-1}$ which was determined for D. magna (OECD, 2004).
Therefore, S. expinosus can be considered a suitable animal model for acute immobilisation tests.

The results from acute immobilisation test show that primulic acid 1 has $\mathrm{EC}_{50}-24 \mathrm{~h}=6.9 \mathrm{mg} \cdot \mathrm{I}^{-1}$ (Fig. 3). According to the Globally Harmonized System of Classification and Labelling of Chemicals (United Nations, 2019), the compound should be classified as a toxic for aquatic organisms. The toxicity of primulic acid 1 is related to its low cmc. Saponin solubilises membranes and causes leakage of intracellular constituents. Primulic acid 1 has high haemolytic activity (25000 - 29000; Steiner and Holtzem, 1955) and membrane toxicity $\left(\mathrm{IC}_{50}=\right.$ $58 \mu \mathrm{M}$; Böttger et al., 2012). Its value of membrane toxicity is lower than the $\mathrm{cmc}$. It means that solubilisation of membranes occurs at a premicellar concentration. Formation of micelles is not required for this process. Böttger et al., (2012) also studied general cytotoxicity of primulic acid on human urinary bladder epithelial carcinoma cells (ECV-304). They obtained lower value $\left(\mathrm{IC}_{50}=13 \mu \mathrm{M}\right)$ for this activity than that of membrane toxicity. It means that cells are affected by primulic acid 1 at a concentration smaller than the concentration causing membrane disruption. Integrity 


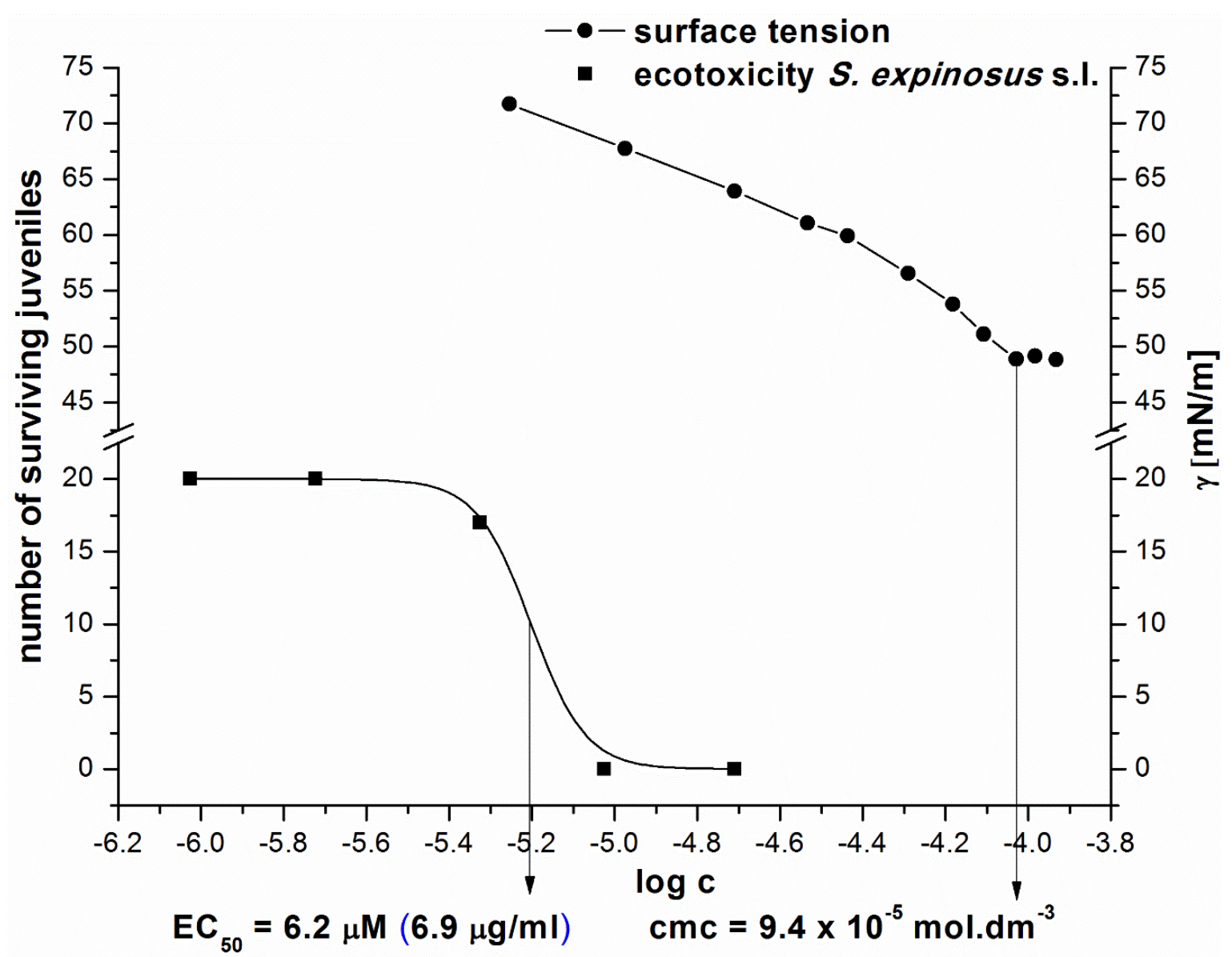

Figure 3. Plot of the number of surviving juveniles of Simocephalus expinosus vs. log concentration of primulic acid 1 (squares) and plot of surface tension vs. log concentration of primulic acid 1 (full circles).

of plasmatic membrane or biochemical processes of cells are held at a concentration that was four and half time smaller than the leakage of intracellular constituents from the cells. The toxicity on the cells corresponds with the toxicity on animals. S. expinosus is sensitive to primulic acid 1 at a half of the concentration determined by Böttger et al., (2012) for ECV-304. The snail Biomphalaria glabrata, responsible for the spread of intestinal schistosomiasis disease is also highly sensitive to primulic acid 1. Its molluscicidal concentration is $7.2 \mu \mathrm{M}$ (Hostettmann et al., 1982).

\section{CONCLUSION}

The present study provides a simple method of isolation of primulic acid 1 from the roots of Primula elatior. The procedure utilises ultrasonic maceration of powdered root in methanol, reverse phase chromatography of the extract on highly porous styrene-divinylbenzene polymer resin and crystallization of saponin. The influence of primulic acid 1 on the environment was evaluated by the acute immobilisation test performed with Simocephalus expinosus s.l. The test showed that the saponin can be classified as toxic for aquatic organisms. The toxicity of primulic acid $1\left(\mathrm{EC}_{50}-24 \mathrm{~h}\right)$ is lower than its value of $\mathrm{cmc}$. We assume the action at the subcellular level and not just solubilisation of a plasmatic membrane which is typical for amphiphilic compounds. Our results show that medicaments containing primula acid 1 or extracts from primula root should be also evaluated in relation to the environment.

\section{ACKNOWLEDGEMENT}

This research was funded by the Grant Agency of Ministry of Education and Academy of Science of Slovak republic (VEGA), Project No. VEGA 1/0054/19. This work was supported by the Slovak Research and Development Agency under the contracts No. APVV-17-0373 and APVV-19-0056. This work utilises the results of the research funded by the Slovak Research and Development Agency Grant No. APVV-0516-12 and by the CEBV project, ITMS: 26240120034. 
[1] Böttger S, Hofamnn K, Melzig MF. Saponins can perturb biologic membranes and reduce the surface tension of aqueous solutions: A correlation? Bioorg. Med. Chem. 2012;20:2822-2828.

[2] Çalis I, Yürüker A. Triterpene saponins from Primula veris subsp. Macrocalyx and Primula elatior subsp. Meyeri. J. Nat. Products 1992;55:1299-1306.

[3] EMA. European Medicines Agency. EMA/424238/2016. (https:// www.ema.europa.eu/en/documents/herbal-summary/primularoot-summary-public_en.pdf) Published September 202016. Accessed October 102020.

[4] Hostettmann K., Kizu H, Tomimori T. Molluscicidal Properties of Various Saponins. Planta Med. 1982;44:34-35.

[5] Hudec I. Výskyt a biológia druhov rodu Daphnia, podrod Ctenodaphnia (Cladocera, Daphniidae) na Slovensku. Biologia. 1989;44:489-498.

[6] Hudec I. Fauna Slovenska III: Anomopoda, Ctenopoda, Haplopoda, Onychopoda. Bratislava, VEDA; 2009.

[7] Kar S, Sanderson H, Roy K, Benfenati E, Leszczynski J. Ecotoxicological assessment of pharmaceuticals and personal care products using predictive toxicology approaches. Green Chem. 2020;22:1458-1516.

[8] Lukáč M, Štátna ochrana prírody Slovenskej republiky:Komplexný informačný a monitorovací system. June 08 2019. (https://www. biomonitoring.sk/OccurenceDataEdit/Zoological/Edit/2902628? ReturnPage=ZooList) Accessed September 252020.
[9] Lukáč M, Pisárčik M, Garajová M, et al. Synthesis, Surface Activity, and Biological Activities of Phosphonium and Metronidazole Salts; J Surfactants Deterg. 2020;23:1025-1032.

[10] OECD. Test No. 202: Daphnia sp. Acute Immobilisation Test. OECD Guidelines for the Testing of Chemicals, Section 2. Paris, OECD Publishing; 2004.

[11] Ph. Eur. 10.0; European Pharmacopoeia, tenth ed. (in English). Council of Europe. Strasbourg, 2019. (https://www.edqm.eu/ en/european-pharmacopoeia-ph-eur-10th-edition) Accessed October 102020.

[12] Regulation (EC) No 1907/2006. Europian Parliament and the Counncil. Registration, Evaluation, Authorisation and Restriction of Chemicals (REACH). (http://data.europa.eu/eli/ reg/2006/1907/2014-04-10). Effective December 18, 2006. Accessed October 21, 2020.

[13] Siems K, Jaensch M, Jakupovic J. Structures of the two saponins isolated from commercially available root extract of Primula sp. Planta Med. 1998;64:272-274.

[14] Steiner M, Holtzem H. Moderne Methoden der Pflanzenanalyse. Peach and Tracy (eds.) Springer Verlag, 1955 Berlin 633 p.

[15] United Nations, Globally Harmonized System of Classification and Labelling of Chemicals (GHS): Eighth Revised Edition. New York, United Nations; 2019. 